\title{
Connecting 3-D Concrete Bridge Design to 3-D Site Measurements
}

\author{
Rauno Heikkilä, Mika Jaakkola \\ Oulu University, Research of Construction Technology \\ P.O.Box 4400 (Kasarmintie 4), FIN-90014 Oulu, Finland \\ rauno.heikkila@oulu.fi.mika.jaakkola@oulu.fi \\ Pekka Pulkkinen \\ ConsultingKORTES Ltd. \\ Rautionkatu 2, FIN-90400 Oulu, Finland \\ pekka.pulkkinen@kortes.fi
}

\begin{abstract}
This paper describes the first results of an R\&D project "Intelligent Bridge" carried out in Finland. The aim of the project is to develop new methods for 3-D design of concrete bridges and further connect and bring the design models to the source information of site measurements. A new design concept for 3-D concrete bridge design was developed and preliminarily tested in a pilot design office. The site tests of the first implementations of real time CAD/CAM measurements using a 3-D robot tachometer, as well as a 3-D laser scanning technique, are presented and evaluated.
\end{abstract}

KEYWORDS: Concrete Bridge Design, 3-D CAD, 3-D Measurements, 3-D Laser Scanners

\section{INTRODUCTION}

The total working process of concrete bridge design and construction is, even today, confused and ineffective. Participants in different phases of this working process use their own methods and tools, which operate, from the total process point of view, insufficiently, partly erroneously, breaking and delaying information chains, and the functionality of direct, effective and accurate refining chains. Considering it geometrically, a bridge element is a part of road geometry. The design process of bridge geometry is operated in a virtual road geometry environment. In Finland, concrete bridge design is mostly carried out using two-dimensional drawing-oriented AutoCAD software tools. At the same time bridge construction sites can already utilize different advanced 3-D measurement techniques. In this situation the required source information has to be planned in a separate working phase using manual user-specific design methods.

At present, design practice design documents, like drawings, quality specifications etc. are produced by 2-D CAD software applications. It is harmful that these design outputs cannot be directly utilized in construction measurements. Instead different human interpretations, format transformations and coding are needed to enable their utilization in site measurements and practical construction. It is clear that if bridge structures were designed as geometrical elements in the same 3-D site coordinate system, including, in addition to geometrical measurements, more intelligent information from the construction of these structures, better utilization of design information could be achieved. On the other hand, lots of different quality control measurements are executed and stored during a bridge construction project process. The results of these inspections are often given to the client without any visualization. If the quality inspection printouts are not introduced in an easy and understandable form, it is difficult to react to deviations and thus the aim of quality control is confused. Present 3-D design technology, however, enables visualization of these deviations.

The aim of this study is restricted to concentrate on this three-dimensional information connection between concrete bridge design and site measurements. The aim is to clear up the problematic field of 3-D concrete bridge design as well as the utilization of these design models in 3D measurements on site. Different types of dvanced 3-D measurement technologies are tested. 


\section{MODERN TECHNOLOGY IN SITE MEASURING}

Ground-based 3-D laser scanners are offering a new technological possibility to geometric control on bridge construction sites. The determination and control of laser scanning accuracy is even today undergoing research and development. Santala and Joala have tested a new calibration method to determine the accuracy and uncertainty of the Cyrax 2500 laser scanner system. In these laboratory test conditions, and in the range of distance $0-50 \mathrm{~m}$, the technical specifications of Cyrax 2500 for single point accuracy $\pm 6 \mathrm{~mm}$ (1 sigma) was verified. In practice, modeled surface precision is better than single point accuracy and equals to $\pm 2 \mathrm{~mm}$ according to the specifications. The consideration of the exact 3-D measurement accuracy for laser scanners is however a complicated research problem and remains to be further studied. [Santala \& Joala]

Foltz has tested the Cyrax 2400 3-D laser scanner in a two-line bridge measurement (1999, Pennsylvania, Lemont, Spring Creek). The scope was, first, to capture a two-lane bridge, including steel and concrete structures, abutments, piers, road surfaces approaching the bridge, terrain under the bridge and adjacent areas, and second, to create as-built 2-D drawings of the bridge and adjacent areas as well as topographic maps of bridge approaches for export to MicroStation. With Cyrax a two-person crew needed three and a half hours to finish 13 scans from five locations to measure the total 3-D scene of the bridge. Compare this to traditional measurement methods: the same bridge was earlier surveyed with two two-person crews over a period of five days. To deliver the required 2-D plan, section and elevation drawings, 28 hours of processing time was needed, which was comparable to the estimated time needed with the traditional measurement and processing methods. [Foltz]

According to McManus, laser scanners have problems in their applicability to bridge measurements. In the measurements of a steel bridge with complicated surfaces and structures (Iron Bridge at Coalbrookdale, UK) both photogrammetric technologies as well as laser scanning ones were used. Finally, less than $1 \%$ of the data in the final bridge model was from the laser scanner. The main reason for this failure was assessed to be the lack of direct edge detection. [McManus]

\section{NEW 3-D DESIGN CONCEPT IN BRIDGE ENGINEERING}

The basic idea in the new 3-D design concept is to utilize the same 3-D model through the construction process, Fig. 1. At the beginning, the designer creates a 3-D model and prepares all the design documents using the model, which is placed in the final position by using the terrain model and coordinate system of the project. The road geometry is specified by the road designer. The bridge designer can transfer the model to the analyzing program in order to make static and dynamic calculations. The designer completes the model by adding material specifications and tolerance requirements into it.

In the next phase, the model with other design documents is transferred to the client, who uses the information in the tender phase. Advantages in the tendering process are the speed of information transfer and the visual superiority of the 3-D model.

In the construction phase all site measuring is done by using coordinate data from the 3-D model in the robot tachometer, as well as a ground-based laser scanner. Only one surveyor with a movable computer is needed for the work. All information needed for measuring is included in the model. After the concrete has hardened, the as-built structure is measured and checked. The information is stored in the model and tolerance comparison is carried out by the special software. All deviations can be visualized.

Finally, when the bridge is completed and the contractor hands over the bridge to the client, all documents with the model are stored in the client's maintenance system. Later on, annual inspection reports are attached to the same documents.

In the project, the new 3-D design concept has been developed and tested in three different bridge cases, Fig. 2-6. 3-D solid models for real bridges 
have been prepared. In the first bridge, (S44), the model was created by utilizing the 3-D terrain model, as well as the 3-D road model, as initial data. The second and third solids were created by utilizing the road models, only without terrain models. The CAD tool was MicroStation version 8 . The solid model of the bridge was designed by extruding the cross-section along the 3-D road lines. The substructures were modeled separately. After modeling, the required 2-D drawings were prepared and printed out from the models according to the traditional working method.

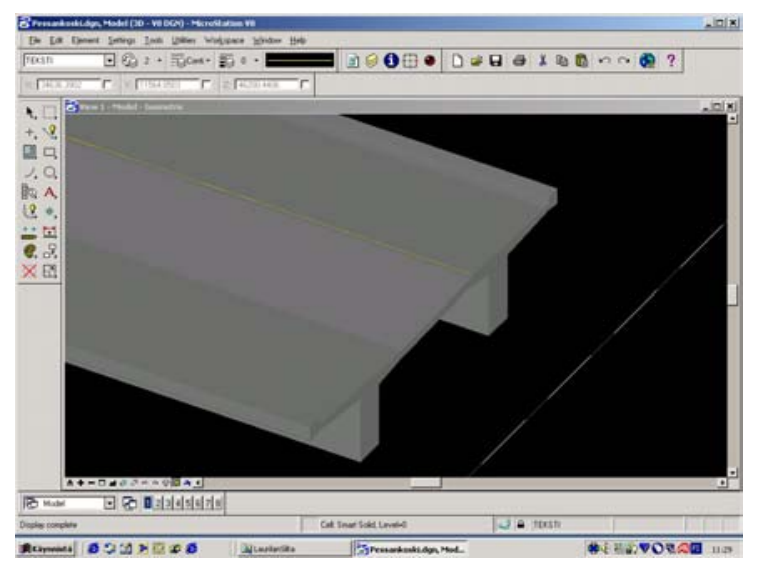

Figure 2. The designed 3-D solid model of Pessankoski Bridge. The solid was prepared by extruding the determined cross-section along the 3-D road lines.

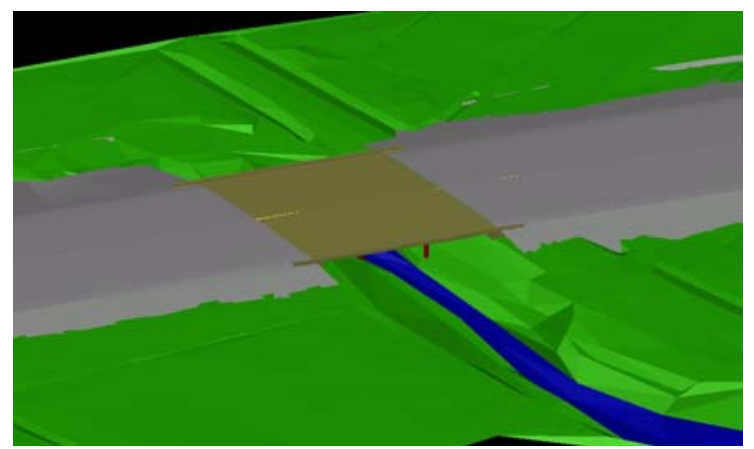

Figure 3. The final combination of 3-D digital terrain model, 3-D road model and 3-D bridge designed solid model (S44 bridge).

The aim was to connect directly the 3-D design model to the 3-D measurements on site. In the case of bridge S44 the solid model was used both to measure and mark the points of steel pipe piles on the ground and later to control the achieved accuracy of the bridge. In the dimension measurements (Fig. 4) a 3-D robot tachometer (Trimble), as a device tool, and MicroStation, as a CAD tool, were used. The final accuracy of the dimension measurements $( \pm 1 \mathrm{~cm})$ was real-time checked by another independent Leica tachometer. For the tests of control measurements, two types of laser scanners were used. Using Callidus, as an example of "dome-like" scanners, two concrete deck slabs were measured, Fig. 5. Cyrax (fanshaped scanner) was also used to measure the final shape of the slab, Fig. 6.

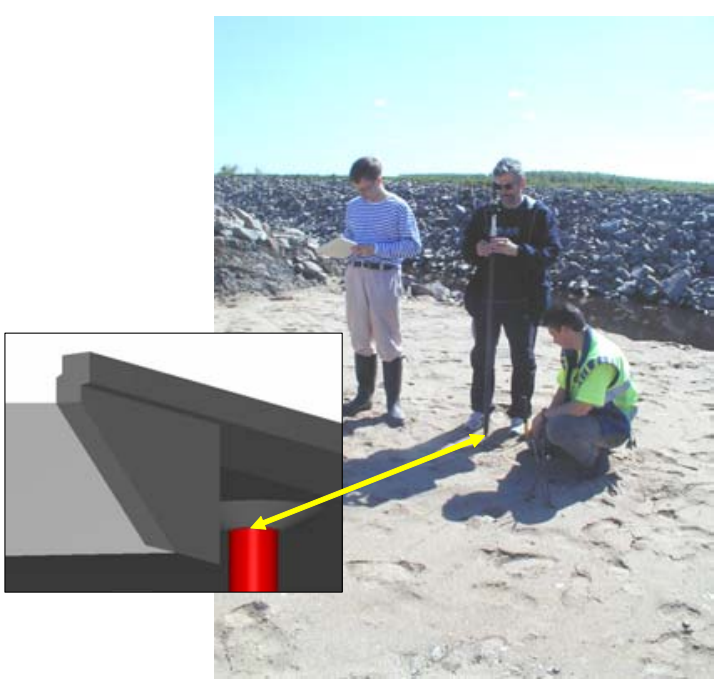

Figure 4. Connecting models to measurements site tests of 3-D design model in real-time 3-D measurements using a robot tachometer as a measurement device (S44 bridge). The designed 3$D$ points of steel pipe piles according to the solid model were measured and marked on the ground..

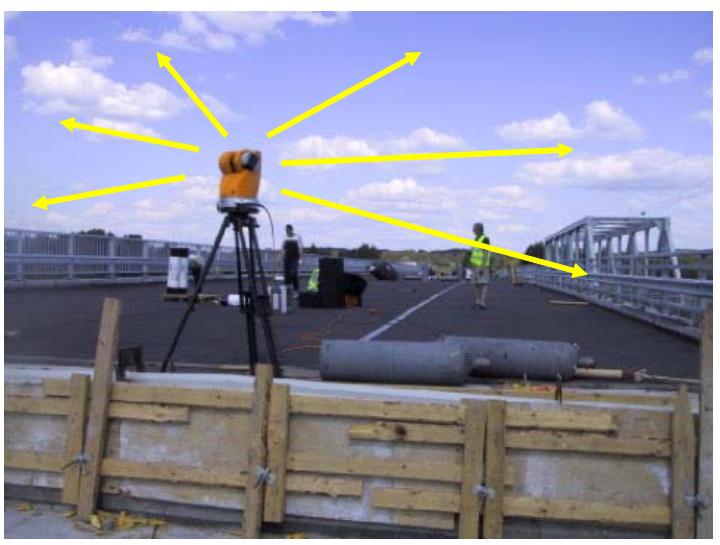

Figure 5. Testing a "dome-like" (Callidus) 3-D laser scanner in the geometric inspection of the concrete deck slab of Pessankoski Bridge. 


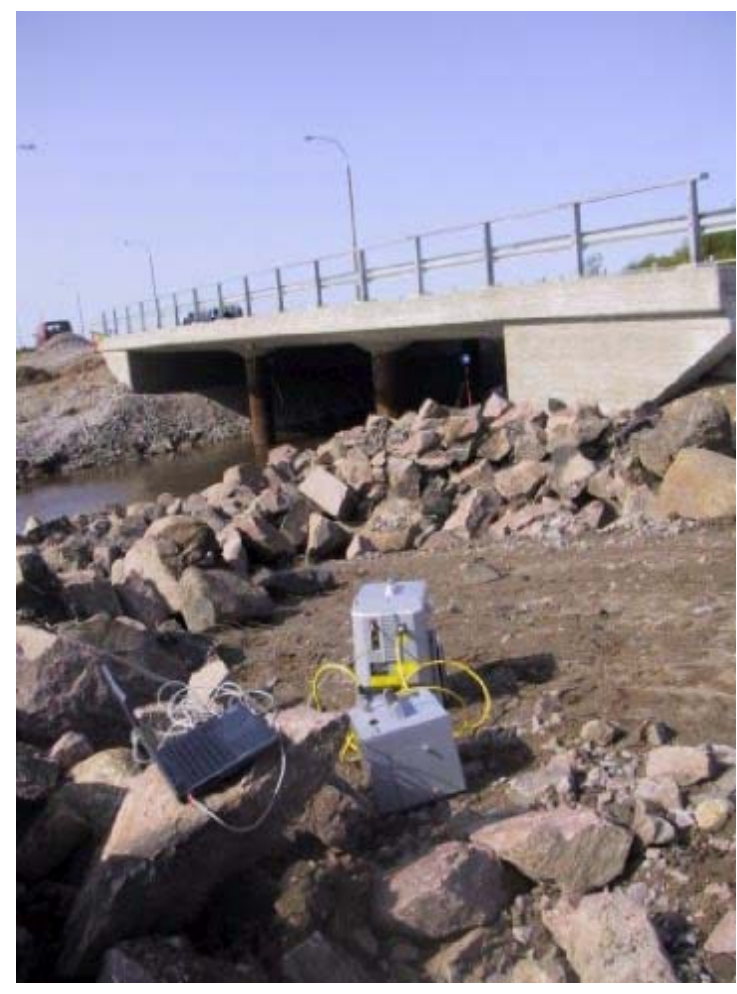

Figure 6. Testing a "fan-shaped" (Cyrax) 3-D laser scanner in the geometric inspection of concrete bridge ( $S 44$ bridge).

\section{RESULTS}

In the design phase the 3-D concept makes design work more demanding while a designer must be able to model the structures, which very often are curved, not straight. The raising of scaffolding is also difficult to process while the final shape of the structure is the most important. For 3-D design of concrete bridge solids, different additional tools are today under development. They are needed for such design tasks as: effect cross-section modeling, the extrusion of crosssection along 3-D road lines and the camber of a structure in measurements.

The first pilot tests have shown the visual superiority of the design concept. For instance, the geometry control survey of steel pipe piles can be visualized easily and the designer can reanalyze the pile system immediately after receiving asbuilt results, Fig. 9. In the construction phase, the connection of the 3-D design model to the site measurements makes it possible to measure and mark points and lines directly on ground or structure surfaces by utilizing the prepared solid model. While the real-time CAD connection can be used no transfer coding and formats are needed.

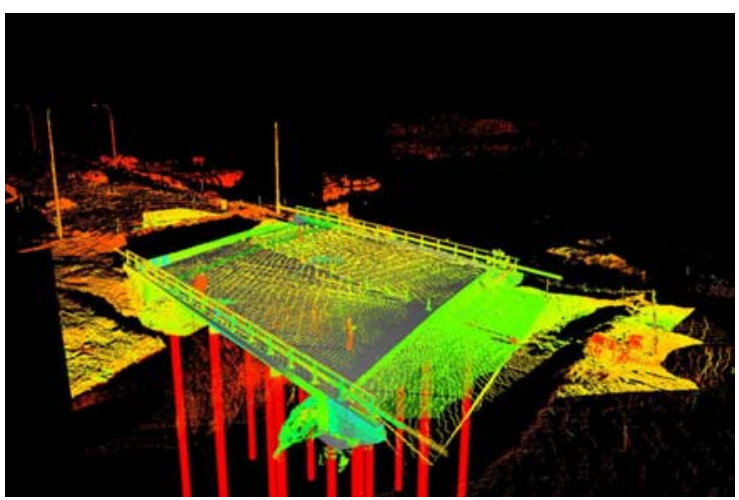

Figure 7. 3-D point cloud of S44 measured by Cyrax 4500 laser scanner. The visible grey levels and red columns are parts of the designed solid model. Using the virtual surveyor method of Cyclon software it is possible to compare the coordinates of designed and measured points of surfaces.

The second extension is that the designed 3-D solid model enables geometric comparison between measured dimensions and shapes, designed ones and tolerances. According to the tests, fan-shaped laser scanners seem to be more applicable to shape measurements of concrete bridge structures.

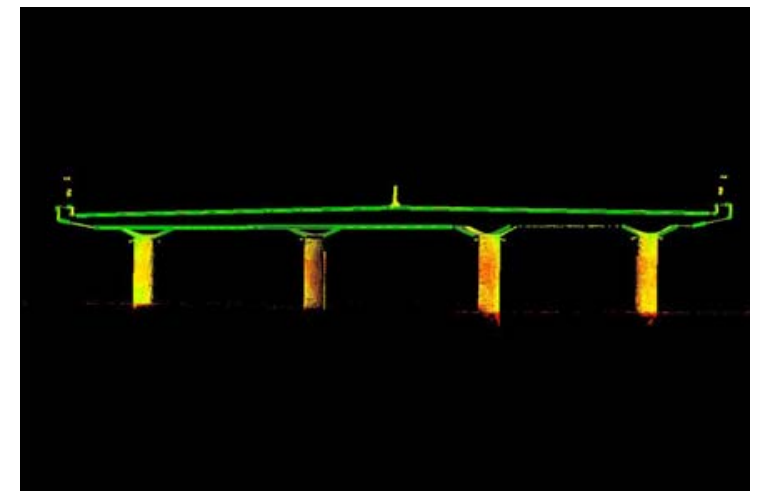

Figure 8. 3-D cross-section taken from the point cloud of S44 measured by Cyrax 4500 laser scanner. 


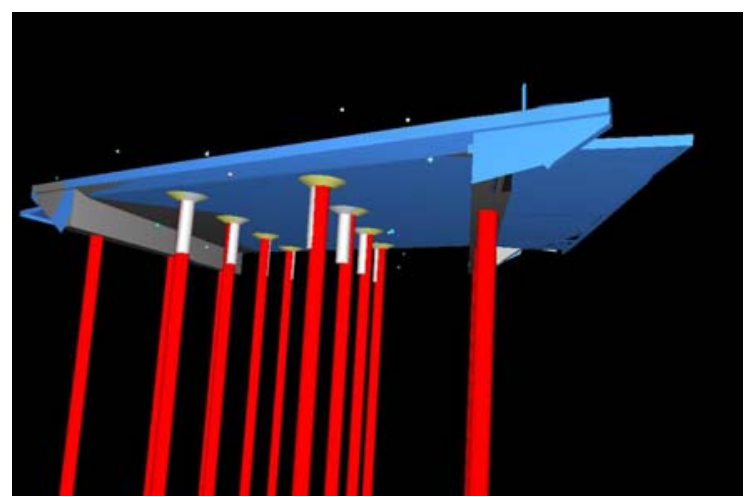

Figure 9. Both the 3-D design and adjusted models of S44 in the same site coordinate system.

In the test measurements of bridge S44, in total, 14 scans and 2,5 million points were needed to form a model of the bridge. Including set-up time, the measurement work was carried out in one working day in the field (one person). In addition, about half an hour was needed afterwards to register multiple scans together and about three hours to create the adjusted model of the bridge, Fig. 7-9. In practice, it is essential to find the required views to capture points from every part of the bridge. The more views and scanner locations needed, the more time is needed for measurements.

\section{CONCLUSION}

In bridge engineering, the information chain of the digital terrain model, 3-D road and bridge design cannot be fully utilized yet. 3-D bridge modeling should be based on terrain and road models in order to ensure faultless bridge solutions. We can evaluate that the 3-D working method will generate benefits both to bridge design and site measurements. In addition, different effects and advantages on other functions in the field of bridge engineering are estimated and can be generated.

In control measurements the effectiveness of laser scanners seems to be essential (compare the results with Foltz). The analyzing software of measurement results should however to be developed. In software comparison tool of measured point cloud to designed 3-D model is missing until now. Also direct tolerance comparison is not possible with the present technology. Deviations should be directly and easily analyzed and compared to the accuracy requirements.

Based on this project, it can be estimated that electronic communication with electronic bridge documentation seems to be the next development in bridge engineering.

\section{REFERENCES}

[CALLIDUS] Callidus precision systems, brochure, 2002, Callidus Presicison Systems $\mathrm{GmbH}$.

[CYRA] CYRA-seminaariaineisto, 2003, Leica Nilomark Oy, Espoo, Seminar Material Folder.

[Foltz] Foltz, L. B., 2000, 3D Laser Scanner Provides Benefits for PennDOT Bridge and Rockface Surveys. Professional Surveyor, May 2000, 4 p.

[Gordon] Gordon, S. \& Lichti, D. \& Stewart, M., 2001, Application of a High-resolution, Groundbased Laser Scanner for Deformation Measurements. The $10^{\text {th }}$ FIG International Symposium on Deformation Measurements, 19-22 March 2001, Orange, California, USA, pp. 23-32.

[Johansson] Johansson, M., 200?, Explorations into the Behaviour of three different highResolution Ground-based Laser Scanners in the Built Environment, pp. 33-38

[Koski] Koski, J., 2003, Laserkeilaus - uusi ulottuvuus paikkatiedon keräämiseen. Maankäyttö 4/2001, s. 24-26.

[Koski] Koski, J., 2002, Laserkeilauksen perusteet ja Cyrax 2500 -laserkeilausjärjestelmä. EspoonVantaan teknillinen ammattikorkeakoulu, Maanmittaustekniikan koulutusohjelma, insinöörityö, $116 \mathrm{~s}$.

[McManus] McManus S., 2002, Secrets of the past. Bd\&e, First Quarter 2002, www.bridgeweb.com, 2 p.

[Santala \& Joala] Santala, J. \& Joala, V., 2003, On the Calibration of a Ground-based Laser Scanner. FIG'2003, Paris, April 13-17, 2003, 7 p. 


\begin{tabular}{|c|c|c|c|}
\hline $\begin{array}{l}\text { 3-D bridge design } \\
\text { 3-D CAD }\end{array}$ & $\begin{array}{l}\text { 3-D measurement } \\
\text { design } \\
\text { 3-D CAD }\end{array}$ & 3-D measurements & $\begin{array}{l}\text { 3-D geometric analyse } \\
\text { 3-D CAD }\end{array}$ \\
\hline $\begin{array}{l}\text { INPUT: } \\
\text { - digital terrain model } \\
\text { - road geometry } \\
\text { ALGORITHM: } \\
\text {-"3-D extrusion" } \\
\text { - "3-D bridge drafting" } \\
\text { OUTPUT: } \\
\text { - 3-D bridge model } \\
\text { - anticipation of } \\
\text { structure deformations }\end{array}$ & $\begin{array}{l}\text { INPUT: } \\
\text { - 3-D bridge model } \\
\text { - needs of site } \\
\text { ALGORITHM: } \\
\text { - selecting the geometric } \\
\text { parts needed } \\
\text { - planning the models for } \\
\text { measurements } \\
\text { OUTPUT: } \\
\text { - points, lines, surfaces, } \\
\text { solides xyz }\end{array}$ & $\begin{array}{l}\text { INPUT: } \\
\text { - designed xyz } \\
\text { ALGORITHM: } \\
\text { - 3-D measurement } \\
\text { techniques and } \\
\text { methods } \\
\text { OUTPUT: } \\
\text { - constructed xyz } \\
\text { - measured xyz } \\
\text { - 3-D points } \\
\text { - 3-D point clouds }\end{array}$ & $\begin{array}{l}\text { INPUT: } \\
\text { - designed xyz } \\
\text { - measured xyz } \\
\text { ALGORITHM: } \\
\text { - modelling measured } \\
\text { objects } \\
\text { - calculation of deviations } \\
\text { - tolerance comparison } \\
\text { OUTPUT: } \\
\text { - measured objects } \\
\text { - geometrical deviations } \\
\text { - tolerance exceedings } \\
\text { - graphical outprints }\end{array}$ \\
\hline
\end{tabular}

Figure 1. The main process of the 3-D concrete bridge design-measurement system. 